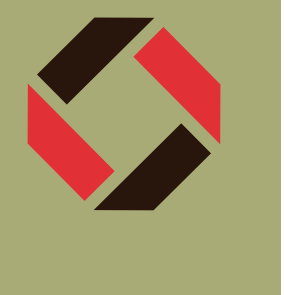

\section{Millie Dresselhaus: Our science celebrity}

\section{By Aditi Risbud}

$\mathrm{R}^{\mathrm{i}}$ isk-taker. Trailblazer. Maverick. These are adjectives often used to describe celebrities and politicians, but rarely attributed to scientists. However, in the case of Mildred Dresselhaus, who died earlier in 2017 at age 86, these superlatives were spot-on.

Dresselhaus, known as the "queen of carbon," was a pioneer in the field of nanoscience. She carried out a series of experiments that led to a fundamental understanding of the electronic structure of semi-metals, especially graphite, along with carbon nanotubes and graphene. A Massachusetts Institute of Technology (MIT) professor emerita of physics and of electrical engineering and computer science, she was also well known for being the first to exploit the thermoelectric effect at the nanoscale, efficiently harvesting energy from the temperature differences in materials that conduct electricity.

The co-author of eight books and some 1700 papers, she supervised more than 60 doctoral students in her 50 years on the MIT faculty. To those in the materials science and engineering community, she was a prolific and innovative scientist, a well-loved mentor, and a role model to hundreds of women (and men) in science and engineering.

"Professor Dresselhaus embodied what a scientist should be: bold, pioneering, kind, and dedicated to making the world a better place," says Jennifer Dionne, an associate professor of materials science and engineering at Stanford University and 2017 MRS Outstanding Young Investigator Award recipient. "She was a huge inspiration for me, and I hope we all can help carry on her legacy for years to come."

Alongside Dresselhaus's outstanding research accomplishments was her long-standing commitment to promoting gender equity in science and engineering. In 1971, she and a colleague organized the first Women's Forum at MIT to discuss the roles of women in science and engineering. She received a Carnegie Foundation grant in 1973 to support her efforts to encourage women to enter traditionally male-dominated fields of science and engineering. For a number of years, she led an MIT seminar in engineering for first-year female students designed to build their confidence.

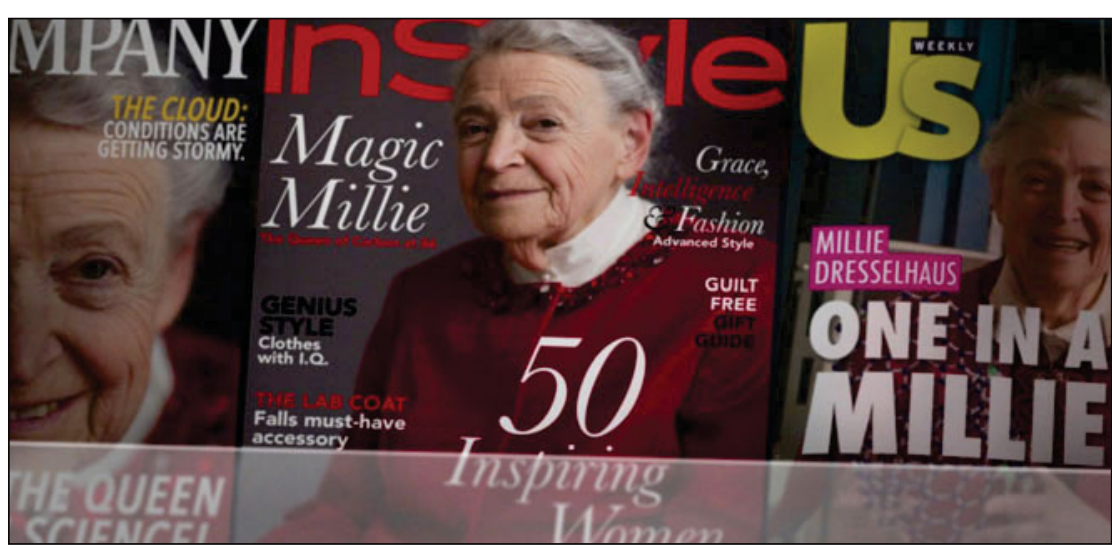

A still image from General Electric's commercial "What If Millie Dresselhaus, Female Scientist, Was Treated Like A Celebrity," featuring a mock fashion magazine with Millie Dresselhaus on the cover. Photo credit: GE.
In 2015, Dresselhaus delivered the keynote address at a three-day workshop for female graduate students and postdocs considering careers in academic research, "Rising Stars." Her remarks, on the importance of persistence, described her interactions with Nobel laureate Enrico Fermi during morning walks to the laboratory at The University of Chicago. Previously, she said during a 2012 interview with the Kavli Foundation, "What I learned from him [Fermi] was the importance of having a very broad understanding of science, so you can take advantage of new science opportunities so that you can really serve society."

In comparison, Dresselhaus noted in the same interview, which she gave when she received the Kavli Prize, "my advisor didn't know what I was working on until two weeks before I submitted my $\mathrm{PhD}$ thesis. He never talked with me because he didn't think women should be in science."

Her primary message to the workshop attendees was persistence. "It was what you did that counted, and that followed me through life," she said.

\section{Celebrating female scientists}

Shortly before her death in February, General Electric (GE) premiered a oneminute commercial envisioning a world in which female scientists held the same cache as celebrities. "Millie" dolls, imagined as a must-have gift for young girls, were juxtaposed with a handful of her real-life achievements: the first woman to win the National Medal of Science, the first woman to become a tenured full professor at MIT, and a recipient of the Presidential Medal of Freedom - the highest award bestowed by the US government upon American civilians.

Asking viewers to imagine "a world where brilliant women in science are treated like stars," the ad aimed to encourage more women to pursue careers in science, technology, engineering, and mathematics, or STEM, fields. In the commercial, girls play with Dresselhaus dolls; girls and young women dress up in wigs and sweaters to resemble their idol. Dresselhaus herself appeared in the commercial, posing for selfies with fans and photographed by paparazzi having lunch with a colleague ("Physics...or 
Chemistry?" read the fictional New York Post cover article).

"We wanted to shine a light on women in STEM and tell the story in a way that was going to engage people. The team came up with this wonderful insight: what if women scientists were as famous as celebrities?" says Linda Boff, vice president and chief marketing officer at GE. Dresselhaus's name came up quickly as a scientist whom the GE research staff admired, both technically and as a person.

Boff notes Dresselhaus's sense of humor, her distinctive look, and her ability to make science accessible. "We were looking for someone with scientific accolades, but also someone who was likable, had charm, and personality, and who had a true commitment to women in the sciences. And Millie Dresselhaus checked those boxes so beautifully."

Directed by Nicole Holofcener (who also directed the movie Enough Said), the commercial aired during the Oscar awards ceremony and was watched by 33 million people. Since then, it has also been watched nearly a million times on YouTube, plus additional viewers on the various cable stations where the commercial airs.

"She was a delight on set-people loved working with her," Boff says. "We were fortunate to be able to work with her and so fortunate that she was able to see this [the ad] before she passed. We kind of feel like the stars aligned a little bit for us."

\section{Balancing the equation}

The commercial was part of a major campaign GE launched earlier this year called "Balance the Equation," with a goal of 20,000 women filling STEM roles by 2020 . The company also aims to recruit $50 \%$ women into all of GE's entry-level technical leadership programs.

"It's very important for young girls to just see women in technical positions, doing math, experimenting and getting their hands dirty to find world-changing answers," says Danielle Merfeld, GE's vice president of global research. "One small thing we've already started doing is sharing vivid portraits of some of the thousands of women doing those things at GE."

Despite recent efforts from academia, government, and industry, only $14 \%$ of

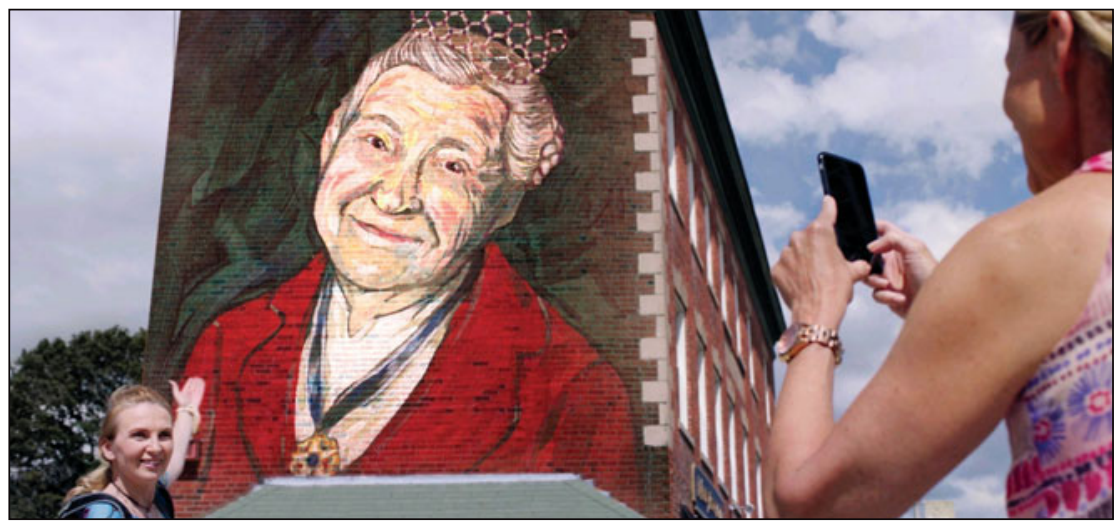

A still image from the GE ad showing a young woman posing for a photo next to a mural of Dresselhaus. Photo credit: GE.

all engineers and $25 \%$ of all IT professionals in the United States are women. Although women make up 55\% of all college and graduate students overall, only $18 \%$ of computer science graduates and $19 \%$ of engineering graduates are female, according to the US Bureau of Labor Statistics.

This gender imbalance continues, or often worsens, when women complete their education and enter the workforce. A 2011 survey of 5500 women with engineering degrees in the United States found that $40 \%$ did not pursue an engineering career after graduation. Among the major tech companies (Facebook, Google, Microsoft, Apple, eBay, LinkedIn, Twitter, and Amazon), women are still significantly underrepresented, holding between $13 \%$ and $24 \%$ of tech-related jobs, and $17-30 \%$ of leadership positions.

While the world has made significant progress in closing the gender gap in health and education, the economic gap remains wide, especially in areas that are vital to growing the economy. According to the Organisation for Economic Co-operation and Development (OECD), a strong negative correlation exists between a country's gender gap and its living standards.

Along with the moral imperative of gender equality, the economic case is equally obvious: In the digital industrial future, companies and countries that cannot close the gender gap will not succeed. Indeed, the OECD estimates that increasing female labor participation could boost gross domestic product between $5 \%$ and $12 \%$ in the next 15 years.
As the pace of innovation accelerates and digital technologies transform the industrial world, both advanced and emerging economies already suffering from a significant skills gap will feel the effects of slowing economic development. The United States alone will need to fill approximately 2 million engineering and computing jobs within the next decade.

Along with the Dresselhaus ad, GE aims to "continue the conversation" on diversity, recently projecting the faces of 12 distinguished female scientists onto the constellation ceiling at Grand Central Station in New York City as part of a three-day event to shine a light on the "unseen stars" of science. These faces included longtime MRS member Sossina M. Haile, the Walter P. Murphy Professor of Materials Science and Engineering at Northwestern University, along with Dresselhaus, who received the 2013 MRS Von Hippel Award in recognition of her outstanding contribution to interdisciplinary research on materials.

"How can you see a brighter future if you only look at half the picture? If the world my company serves is half men and half women, shouldn't we have a team that represents that population?" GE's Chief Technology Officer and Senior Vice President Victor Abate wrote in a GE Report.

Given her trailblazing work, inviting Dresselhaus to represent GE's campaign in the ad was ideal. Among the materials research community and scientists in general, she was already a celebrity. 